\title{
Relationship of Values and Personality Traits in Malaysian College Students
}

\author{
Mazni Mustaphaa, ${ }^{a}{ }^{*}$, Michael E. Hyland ${ }^{b}$ \\ ${ }^{a}$ Faculty of Psychology and Education, Universiti Malaysia Sabah, Jalan UMS, 88400 Kota Kinabalu, Malaysia \\ ${ }^{b}$ School of Psychology, Plymouth University, Drake Circus, Plymouth, PL4 8AA, Devon, United Kingdom
}

*Corresponding author: masni@ums.edu.my

\begin{abstract}
The purpose of our study was to investigate the relationships between personality traits and value importance amongst students at tertiary level of education in Malaysia. Two thousands and ninety students from various government and semi-government's higher learning institutions participated in this study. The Schwartz's Short Value Scale (adapted version by Lindeman \& Verkasaloo, 2005) was used as a measurement tool for value importance. All of 10 universal values i.e. Power, Hedonism, Self-direction, Stimulation, Achievement, Benevolence, Universalism, Tradition, Conformity, and Security as proposed by Schwartz (1992), were rated on the extent to which they act as "guiding principle of life". Two underlying structures of values were identified as Conservation and Self-Transcendence. Personality traits were based on the five factor model of personality, i.e. Openness to experience, Conscientiousness, Extraversion, Agreeableness, and Neuroticism, measured through The Big Five Inventory by John, Donahue, and Kentle (1991). Results showed that Agreeableness and Conscientiousness were positively correlated with both Conservation and Self-Transcendence values. Whilst, Openness showed negative relationships with both types of values, and Neuroticism correlated negatively with Self-Transcendence values.
\end{abstract}

Keywords: Value importance; values, Schwartz Value Theory; personality traits; big five personality

(C) 2017 Penerbit UTM Press. All rights reserved

\subsection{INTRODUCTION}

Values and personality are two important psychological features that often lead to the prediction of different types of behaviours. Values and personality are believed to be related to one another, in that values might be shaped by personality traits. Traits are enduring characters of human beings that are associated with consistent patterns of thought and feelings (Costa \& McCrae, 1990). Traits are believed to have a genetic component (Loehlin, McCrae, Costa, \& John, 1998). However, their emergence and interaction with environmental stimuli may have some impacts on the shaping of values and attitudes that relate to the values (McAdams \& Pals, 2006; Rokeach, 1973). The present study demonstrated associations between personality traits and the importance of values amongst Malaysian college students.

\subsection{DEFINITIONS AND THEORETICAL UNDERPINNINGS}

\section{Definition of Values}

Values have been understood by scholars of various disciplines as the criteria people use to evaluate actions, people, including the self, and events (McGuire, 1968; Schwartz, 2003). According to Martynowiez (2006), people evaluate actions based on what they perceive as "ought to" be done or following what has been normally accepted in the society.

Rokeach (1973) defines values in a much broader perspective as he ability to unify the apparently diverse interests of all the sciences concerned with human behaviour, while Schwartz (1990) defines values in a narrower sense as: "people's conceptions of the goals that serve as guiding principles in their lives" (p. 142). Locke \& Henne (1986) describe goals as "a means of actualising value..." which are "the mechanism by which values are translated into action" (Park \& Guay, 2009).Values express basic human needs (Schwartz, 1992) that are necessary or required in life, and also things that are desirable, worthwhile and important (Roccas, Schwartz, \& Amit, 2010). As motives are a cognitive representation of a goal regardless of having a connection to either action or affect, therefore values can also be considered as an individual's motives (Feather,1995; Kagan, 1972).

\section{Definition of Personality}

Personality has been described as "consisting of more or less stable internal factors that make one person's behaviour consistent from one time to another, and different from the behaviour other people would manifest in comparable situations" (Eysenck, 1991). Personality is believed to be determined by biological processes, which result in certain types of predispositions within individuals. These predispositions - otherwise known as temperament - describe an individual's typical moods and activity level which is assumed to be largely determined by heredity (Eysenck, 1991). The assumption that the invariance of personality would be reflected in the stable rank-ordering of individuals in 
their behaviour in any given dimension assessed with the cross-situational consistency coefficient has been challenged by persistent findings that yielded low correlations in the individual's behaviour found from one situation to another, which has led to a prolonged "person vs. situation" debate in personality research (Mischel, 2004). As there is a need to consider both person and situation in explaining an individual's behaviour, the social cognitive view of personality was proposed which took "into account the situation and its meaning for the individual, and may be seen in the stable interactions and interplay between them" (Mischel, 2004).

Personality also has been referred to an individual's unique pattern of traits - any "distinguishable, relatively enduring way in which one individual differs from others" (Bilsky \& Schwartz, 1994). A working definition of personality in this research is described by John, \& Srivastava (1999) through the 44 items of the Big Five Inventory (BFI).

\section{The Big Five Personality Theory}

The Five Factor Model of personality has been assumed to derive from Cattell's (1943) pioneering study in identifying a shared taxonomy of standard applicable personality adjectives (John, Naumann, \& Soto, 2008). As a starting point, based on Allport \& Odbert's (1936) list of personality lexicons, Cattell made a massive reduction from 4,500 trait terms to 35 variables (John, Naumann, \& Soto, 2008). He then performed several oblique rotational factorial analyses on the variables, and finally came out with twelve factors which formed a part of the 16 personality factors (John, Naumann, \& Soto, 2008). The validity and reliability of Cattell's 16 personality factors have been questioned by other scholars. For example, Barrett \& Kline (1982) ran extensive factorial analyses on a sample of data on 491 university students and suggested that only between 7 to 9 factors were verified. This has inspired researchers to undertake further investigations, such as Fiske (1949) who constructed much simplified descriptions of Cattell's variables and found a similar factor structure of personality across different types of rating system; and Tupes \& Christal (1961) who reanalysed Fiske's factors across different samples and rating systems, eventually finding five relatively strong factors (John, Naumann, \& Soto, 2008).

This five-factor structure was replicated by a few researchers later on, including Norman (1963) who labelled the factors as: "(i) Extroversion or Surgency (talkative, assertive, energetic) (ii) Agreeableness (good-natured, cooperative, trustful), (iii) Conscientiousness (orderly, responsible, dependable), (iv) Emotional stability vs. Neuroticism (calm, not neurotic, not easily upset), and (v) Culture (intellectual, polished, independent-minded)" (John, Naumann, \& Soto, 2008).

Five factors have been assessed in the 240 items of the Revised NEO Personality Inventory (NEO-PI-R) or the briefer 60-item NEO Five Factor Inventory (NEO-FFI) (Costa Jr, \& McCrae, 1990). Goldberg (1992) also developed 100-unipolar item and 50-bipolar item trait descriptive adjective checklists to assess the five factors. Later, the Big Five Inventory (BFI) was developed which consisted of 44 items (John \& Srivastava, 1999). The reliability and validity of these instruments were reported to be good (Carr, 2004). The five factors are known as: Extroversion, Conscientiousness, Agreeableness, Openness, and Neuroticism. Brief explanations on each of the five factors are as follows Carr (2004): (a) Extroversion is associated with good social adjustment and success in leadership, management and sales positions, (b) Emotional stability, which is the opposite end of Neuroticism, is associated with good mental health and physical health, (c) Openness to experience is associated with creativity and a disposition towards absorption and peak experiences, (d) Agreeableness is associated with altruism, good interpersonal relationships, within work and social contexts, and (e) Conscientiousness is highly predictive of occupational performances.

\section{Theory Of Values}

Schwartz $(1992,2003)$ proposed a unifying theory of human motivation, encapsulating aspects of different needs, motives and goals, later known as the theory of basic values. According to Schwartz, values may contradict one another, while others are congruent. However, the degree of importance attributed to each value may vary across culturally diverse groups. The working definition of values throughout this research is based on Schwartz (2003) explanation on ten universal values; Power, Achievement, Hedonism, Stimulation, Self-direction, Universalism, Benevolence, Tradition, Conformity, and Safety, that are believed to be importance as they are guidance principles of a person's life.

The common structure of value types consists of 4 higher order value types that form two bi-polar dimensions. The first dimension is called "openness to change vs. conservation" as it locates a combination of stimulation and self-direction values in opposition to a combination of security, conformity and traditional values. The second dimension is called "self-enhancement vs. self-transcendence" as it places a combination of power, hedonism, and achievement in opposition to a combination of universalism and benevolence values. Schwartz (1992) suggested that there could be more variants of the alternative value structure, as the results displayed deviations from the ideal structure, mostly amongst samples from several countries which shared a common feature of having less exposure to Western culture. The structure of the values is depicted in the circular diagram in Figure 1. 


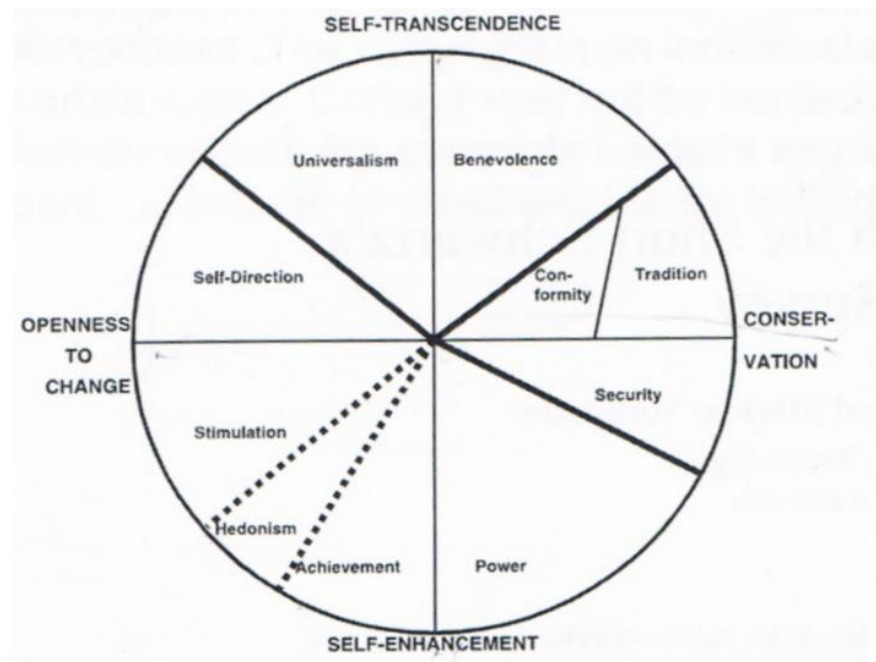

Figure 1 The theoretical structure of relations among motivational types of value (Source: Schwartz, 1992)

\subsection{LITERATURE REVIEW}

Relationships Between Values and Personality

The relationship between the personality traits and values has been noted by several scholars. Rokeach (1973) mentioned that personality traits can be "reformulated from an interval, phenomenological standpoint as a system of values" (p. 20). In Furnham (1984) study among 70 college students, using the Eysenck Personality Questionnaire and Rokeach Value Survey, it was found that unstable introverts rated "freedom" and "self-respect" more highly than the other groups - stable introverts, unstable extroverts and stable extroverts. The neurotics rated "inner harmony" more and "comfortable life" less highly than non-neurotics, whereas stable and unstable extroverts rated an "exciting life" more than stable and unstable introverts. Furnham concluded that the more fearful, conforming and neurotic a person is, the more likely he or she will be to have a conservative mind; whilst the more impulsive, risk-taking and extroverted the person is the more radical he or she is. These results suggested that people of different needs and self-concepts would also be different in the importance of their values.

Pozzebon \& Ashton (2009) ran a self and peer-reported survey of values, value-related behaviours and personality amongst 252 university students in America, and found that correlations existed between personality dimensions and values. In their study, the Schwartz Value Scale (SVS) and the HEXACO Personality Inventory (HEXACO-PI) were used to measure value and personality. The HEXACO Personality Inventory assesses the broad dimensions of personality: Honesty-Humility, Emotionality, Extroversion, Agreeableness, Conscientiousness and Openness to Experience. The current study used the shorter version of the HEXACO-PI, in which there are 16 items for each of the six broad factor-level scales presented with a 5-point response scale $(1=$ strongly disagree to $5=$ strongly agree $)$. Five correlations were found between the scales. The personality dimension Honesty-Humility negatively correlated with Power $(\mathrm{r}=-.53)$ and positively correlated with Benevolence $(\mathrm{r}=.45)$ and Universalism $(\mathrm{r}=.36)$, whilst Openness to experience correlated positively with SelfDirection $(\mathrm{r}=.38)$ and Universalism $(\mathrm{r}=.42)$.

Haslam, Whelan, \& Bastian (2009) found that the personality dimension Extroversion correlated the most with Stimulation, Hedonism and Self-direction values (which falls in the "Openness to change" component), agreeableness with Benevolence ("prosocial values"), Conscientiousness with "conservation values" (Conformity, Tradition and Security), Openness with "Self-transcendence", and "Openness to change" (e.g. Universalism, Self-direction, Stimulation). Neuroticism had a positive association with traditional values and a negative relationship with Stimulation.

Studies on values in Malaysian samples have been conducted in various perspectives, including the relations between 'internet ethics' and the big five personality traits amongst students (Karim, Zamzuri, \& Nor, 2009). Comparison studies in education involving different ethnic groups (Fung, 2010) or countries (Malaki, Soriano, \& Valdez, 2009), body image issues (Swami \& Tovée, 2005), teenage admired values (Abdullah Yusof \& Mohd Amin, 1999), preferences for shopping decisions and TV advertising content preferences (Ramaprasad, 1998), creating, testing and elaborating a model of values on a Malaysian sample (Keats, 1986), and in-depth understanding of a particular ethnic group in Malaysia (e.g. Malay folk beliefs (Osman, 1989)). However, to the researchers' knowledge, there is no such empirical data on the link between personality and universally accepted values. Therefore, the aim of the study is to fill this gap, starting with examining the relationship between personality and importance of values in a population of Malaysian students.

\subsection{METHODOLOGY}

\section{Sampling}

Participants were recruited among students at various colleges in Kuala Lumpur and its surrounding areas and in a public university in Sabah, Malaysia. Seven hundred and eighty-one (37.4\%) male and $1308(62.6 \%)$ female college students with a mean age of $19.78(\mathrm{SD}=1.19)$ 
participated in this study. One thousand two hundred and thirty $(61.1 \%)$ of them were Malays, $331(16.5 \%)$ Chinese, 74 (3.7\%) Indians, 289 (14.4\%) Bumiputera Sabah (the indigenous people of Sabah), 73 (3.6\%) Bumiputera Sarawak (indigenous people of Sarawak), and 15 (0.7\%) others. Seventy-eight participants did not state their ethnicity. One thousand and five participants $(72.2 \%)$ had never been overseas before. Of total population, $53.7 \%$ was reported to be awarded with scholarships of Malaysia government.

\section{Study Design And Measurement}

The study was designed to be in a survey form. Participants were asked to complete a set of questionnaire. As the scales used in the questionnaire was originally in English, translation was required. In the translation process, the scales were first translated by the researcher into target language (i.e. the Malay language). The translated and the original version of the scales were given to three Malay-English bilinguals who sat together to discuss about the quality of the translation. Upon agreement of all of the translators, very little amendments were made to the translation as to suit with the English version without changing the meaning of the words. The questionnaire used in the rest of the study had been based on this version of translated scales.

\section{Schwartz's Short Value Scale (SSVS)}

A short version of Schwartz Value Scale (SSVS) (adapted from Schwartz, 1992) containing a single item that measured of each of the following 10 values; Power, Achievement, Hedonism, Stimulation, Self-direction, Universalism, Benevolence, Tradition, Conformity, and Safety, as a guiding principle in life (adapted by Lindemann \& Verkasalo, 2005). For example, participants were asked to rate the importance as a life-guiding principle of "Power that is, social power, authority, wealth" and "Achievement, that is, success, capability, ambition, and influence on people and events." A similar phrasing was used for all 10 values. Hence, the SSVS included 10 items, each of which indicated one original value and the related original value items as descriptors. The 10 value items were rated on a 9-point scale ranging from 0 (opposed to values), 1 (not important), 4 (important), to 8 (of supreme importance). Higher scores on this scale indicate greater importance of values.

Lindemann \& Verkasalo (2005) ran a multidimensional scaling analysis and found that two-dimensional structure of values (Conservation vs. Openness to change and Self-transcendence vs. Self-enhancement) were also existed within the SSVS. Results showed that the value structure of SSVS was similar to the circumplex model proposed by Schwartz $(1992 ; 1994)$. High positive correlations were also shown between the SVVS and the SVS ( $\mathrm{r}$ ranged between 0.45 and .70), indicating both of scales are mutual. As SSVS is as credible as the original SVS, this short version is obviously beneficial in research as less time consuming for participants to answer it. Lindemann \& Verkasalo (2005) developed two different equation formulas, measuring the degree of importance for the two value dimensions, for a 7 and 9-point scales, which the latter had been adopted to be used in this research. The followings are the equation formulas used in this research:

Self-transcendence importance/ satisfaction $=-.60-(.19 \mathrm{x}$ Power $)-(.14 \mathrm{x}$ Achievement $)-(.09 \mathrm{x}$ Hedonism $)-(.11 \times$ Stimulation $)+(.01 \times$ Self-direction $)+(.10 \times$ Universalism $)+(.13 \times$ Benevolence $)$ $+(.07 \times$ Tradition $)+(.06 \times$ Conformity $)+(.02 \times$ Security $)$

Conservation importance/satisfaction $=.82+(.05 \times$ Power $)+(.06 \times$ Achievement $)-(.04 \times$ Hedonism $)$ $-(.09 \mathrm{x}$ Stimulation $)-(.18 \mathrm{x}$ Self-direction $)-(.16 \mathrm{x}$ Universalism $)+(.03 \mathrm{x}$ Benevolence $)+(.16 \mathrm{x}$ Tradition $)+(.18 \times$ Conformity $)+(.11 \times$ Security $)$

Based on the original SSVS, following the same sequence of items and structure, another value scale was adapted in order to measure satisfaction felt when goals related to each of the values are achieved. Answers were scaled on a 9-point scale, ranging from 0 ('not relevant to my values') to 8 ('completely satisfied'). Higher scores on this scale indicate greater satisfaction of values.

\section{Big Five Inventory (BFI)}

The 44-item inventory of John, Donahue, \& Kentle (1991) was used to assess the Big Five personality factors i.e. Extraversion (E) 8 items, Conscientiousness (C) 9 items, Openness (O) 9 items, Agreeableness (A) 8 items, and Neuroticism (N) 10 items. Sixteen items were identified as negative items, which were then reverse-coded, which means that a score 1 becomes 5, 2 becomes 4, 3 remains 3, 4 becomes 2 , and 5 becomes 1 . Cronbach's alpha for this inventory ranged from 0.55 to 0.76 , indicating that the scale was adequately reliable to be used. An exploratory factorial analysis was run on the data to determine the structure of the inventory as previous studies had shown different results of the underlying personality factors or traits.

\section{Procedure}

Before commencing into the study, a special permission for the study need to be gained first from the Ministry of Higher Education Malaysia. After the permission sought, each of the institutions, around Kuala Lumpur and its surrounding areas was contacted. It was preceded by several phone calls, and subsequently by formal letters. Later, an appointment was made with the staffs of students' affairs department of each institution to explain and discuss further about the study. As students came from various studying programme, their time table were different from one another. Thus, administration of the questionnaires was foreseen as problematic.

At the time of the study was conducted the students were preparing for their final examination, which added to the difficulties of the study to run smoothly. Thus, assistance in administering and collecting back the questionnaires was requested from the institutions to smooth down the process. An announcement about the study was made by the staffs to a group of prospective participants during classes, and they were told that participation to the study is voluntary. Questionnaires were administered during classes, which however, were not collected 
right away. Instead, the students were asked to fill in the questionnaire at their convenient time, and to return it to the personnel in-charge within two weeks. Every student who was willing to take part in the study was given a research information sheet for reference and a consent form to be completed and signed. Two weeks later, the questionnaires, together with the consent forms were collected back by the researcher.

In other cases, we were given the opportunity by the institution to handle the administration of the questionnaires to the participants by ourselves. Every participant was asked to fill in the consent form and was given the research information sheet for reference. Before distributing the questionnaires, a brief explanation was given about the study. The participants were told they were free to ask questions if there was anything unclear to them. The questionnaires were completed in about 20 minutes. Participants were asked whether they have any questions in the end of the session, and asked to contact the researchers via email (the researchers' contact details were provided in the research information sheet) if they need further explanation about the study or if they wish to withdraw from the study.

\section{Method Of Analysis}

Data were entered and analysed through the SPSS version 18. Before performing any inferential analysis, normality tests were run first on the data to ensure that the data were normally distributed. In order to test the hypotheses, Pearson correlation tests were used.

\subsection{RESULTS AND DISCUSSION}

Self-transcendence and Conservation Importance had consistently shown positive correlations with dimension personality Agreeableness and Conscientiousness ( $\mathrm{r}$ ranged from .17 to .33); whilst no significant associations were found between the value variables and Extraversion. Both Openness and Neuroticism correlated negatively with Self-transcendence Importance, which however is very small (both $\mathrm{r}=-.05)$. As expected, a negative correlation occurred between Openness and Conservation importance ( $\mathrm{r}$ ranged from -.05 to -.14). Table 1 displays the results.

Table 1 Correlation results

\begin{tabular}{llllllll}
\hline & $E$ & $A$ & $C$ & $N$ & $O$ & $S T I$ & $C I$ \\
\hline$E$ & - & & & & & \\
$A$ & $.40^{* *}$ & - & & & & \\
$C$ & $.42^{* *}$ & $.55^{* *}$ & - & & & \\
$N$ & $-.39 * *$ & $-.40^{* *}$ & $-.45^{* *}$ & - & & \\
$O$ & $.38^{* *}$ & $.21^{* *}$ & $.32^{* *}$ & $-.19 * *$ & - & & \\
$S T I$ & -.01 & $.33^{* *}$ & $.17^{* *}$ & $-.05^{*}$ & $-.05^{*}$ & - & - \\
$C I$ & .01 & $.23^{* *}$ & $.17^{* *}$ & .01 & $-.14^{* *}$ & $.29 * *$ & - \\
\hline Mean & 27.55 & 35.34 & 31.33 & 22.46 & 33.61 & 22.12 & 36.89 \\
S.D. & 4.92 & 5.00 & 4.89 & 5.02 & 4.31 & 5.53 & 5.82 \\
\hline
\end{tabular}

Note: $*_{p}<0.05$, **p<0.01 (two-tailed), S.D. = Standard deviation, E= Extraversion, A= Agreeableness, C= Conscientiousness, $N=$ Neuroticism, $O=$ Openness, $L S=$ Life satisfaction, $P A=$ Positive affect, $N A=$ Negative affect, $S T I=$ Self-transcendence Importance, CI=Conservation importance

Based on the results, it is indicated that individual's personality may have impact on which values that serve as the guiding principle to a person's life. Being agreeable and conscientious are both positive traits in human being that predispose people towards self-transcendence values, such as being generous to people (e.g. of benevolence) and feeling responsible for the welfare of others (e.g. of universalism). Whilst conservative features, such as being compliant, compassionate and cooperative are already embedded in the personality trait of Agreeableness and Conscientiousness which has unsurprisingly contributed to the importance of conservation values. These conservative characteristics also form the nature of collectivism, which has been found to be highly related to Agreeableness (Benet-Martínez \& Karakitapŏglu-Aygün, 2003). In Malaysian societies, personality traits as such blend well with people's aspirations that incline towards collectivistic values. Furthermore, Agreeableness and Conscientiousness that are already embedded in the Malaysian culture serve other important functions to the society, which is to foster harmony within the society. A study by Benet-Martínez \& Karakitapŏglu-Aygün (2003), supported the finding in which Agreeableness directly predicted self-transcendence values, and indirectly predicted emphatic self-efficacy beliefs and prosociality in young adults in Italy.

Additionally, being less open-minded and more introverted adds other attributes to the values. Hence, people with these traits (e.g. Openness) are anticipated to be governed by their conservation values and less likely to engage in any disclosures. The finding suggested that neurotic individuals as well may not likely to surpass or share their resources, energy, or even idea with others. 


\subsection{CONCLUSION}

Personality traits do have connection with the values that we hold. The traits that are prominent to individuals will be more noticeable and received more attention if they are congruent to the values of the society at large. In short, personality trait Agreeableness, Conscientiousness, and Openness relates well to the importance of conservation and self-transcendence values in this Malaysian population of college students.

\section{References}

Abdullah Yusof, S., \& Mohd Amin, R. (1999). Admired Values: The Case Of Teenagers in Malaysia. International Journal of Social Economics, $26(6), 802-811$. Allport, G. W., \& Odbert, H. S. (1936). Trait-Names: A Psycho-Lexical Study.Psychological Monographs, 47(1), i.

Barrett, P., \& Kline, P. (1982). An Item And Radial Parcel Factor Analysis Of The 16PF Questionnaire. Personality and Individual Differences, 3(3), 259-270

Benet-Martínez, V., \& Karakitapŏglu-Aygün, Z. (2003). The Interplay Of Cultural Syndromes And Personality In Predicting Life Satisfaction: Comparing Asian Americans and European Americans. Journal of Cross-Cultural Psychology, 34(1), 38-60.

Bilsky, W., \& Schwartz, S.H. (1994). Values And Personality. European Journal of Personality, 18, 163-181.

Caprara, G. V., Alessandri, G., \& Eisenberg, N. (2011). Prosociality: The Contribution Of Traits, Values, And Self-Efficacy Beliefs. Journal of Personality and Social Psychology. 102(6):1289-1303. September 26. Advance Online Publication. Doi: 10.1037/a0025626.

Carr, A. (2004). Positive Psychology: The Science Of Happiness And Human Strengths. Routledge: London.

Cattell, R. B. (1943). The Description Of Personality: Basic Traits Resolved Into Clusters. The Journal Of Abnormal And Social Psychology, $38(4), 476$.

Costa Jr, P. T., \& McCrae, R. R. (1990). Personality Disorders And The Five-Factor Model Of Personality. Journal Of Personality Disorders, 4(4), 362-371.

Eysenck, H.J. (1991). Dimensions of Personality: 16, 5 Or 3? - Criteria For A Taxonomic Paradigm. Personality and Individual Differences. 12(8), 773-790.

Feather. N. T. (1995). Values, Valences \& Choice: The Influence Of Values On The Perceived Attractiveness And Choice Of Alternatives. Journal Of Personality And Social Psychology, 68, 1135-1151.

Fiske, D. W. (1949). Consistency of the Factorial Structures Of Personality Ratings From Different Sources. The Journal of Abnormal and Social Psychology,44(3), 329.

Fung, L.Y. (2010). A Study On The Learning Approaches Of Malaysian Students In Relation To English Language Acquisition. American Journal of Scientific Research, 9, 5-11.

Furnham, A. (1984). Personality and Values. Personality and Individual Differences, 5(4), 483-485.

Goldberg, L. R. (1992). The Development Of Markers For The Big-Five Factor Structure. Psychological Assessment, 4(1), 26.

Haslam, N., Whelan, J., \& Bastian, B. (2009). Big Five Traits Mediate Associations Between Valus And Subjective Well-Being. Personality and Individual Differences, $46,40-42$.

John, O. P., Donahue, E. M., \&Kentle, R. L. (1991).The Big Five Inventory - Versions 4a and 54. Berkeley, CA: University of California, Berkeley, Institute of Personality and Social Research.

John, O. P., \& Srivastava, S. (1999). The Big Five Trait Taxonomy: History, Measurement And Theoretical Perspectives. In L. A. Pervin \& O. P.John (Eds.).Handbook Of Personality: Theory And Research, 102-138. New York: Guilford.

John, O. P., Naumann, L. P., and Soto, C. J. (2008). Paradigm Shift to the Integrative Big-Five Trait Taxonomy: History, Measurement, and Conceptual Issues. In O. P. John, R. W. Robins, and L. A. Pervin (Eds.), Handbook of personality: Theory and research (pp. 114-158). New York, NY: Guilford Press.

Kagan, J. (1972). Motives and Development. Journal of Personality and Social Psychology, 22(1), 51-66.

Karim, N.S. A., Zamzuri, N.H.A., \&Nor, Y.M. (2009). Exploring The Relationship Between Internet Ethics In University Students And The Big Five Model Of Personality. Computers \& Education, 53(1), 86-93.

Keats, D.M. (1986). Using the Cross-Cultural Method To Study The Development Of Values. Australian Journal of Psychology,38(3), 297-308

Lindemann, M., \& Verkasalo, M. (2005). Measuring Values with the Short Schwartz's Value Survey. Journal of Personality Assessment, 85(2), $170-178$.

Locke, E. A., \& Henne, D. (1986). Work Motivation Theories. International Review of Industrial and Organizational Psychology, 1, 1-35.

Loehlin, J. C., McCrae, R. R., Costa, P. T., \& John, O. P. (1998). Heritabilities of Common And Measure-Specific Components of the Big Five personality Factors. Journal of Research in Personality, 32(4), 431-453.

Malaki, A.M.S., Soriano, M.S.T.Z., \& Valdez, F.M. (2009). Asian Values And Epistemological Beliefs As Predictors Of Valuing Education. The International Journal of Research and Review, 1, 1-36.

Martynowiez, E. (2006). Values Accepted Youth. US-China Education Review, 3(3), 9-16.

McAdams, D. P., \& Pals, J. L. (2006). A New Big Five: Fundamental Principles For An Integrative Science Of Personality. American Psychologist, 61 (3), 204.

McGuire, W. J. (1968). Personality and Susceptibility To Social Influence.Handbook Of Personality Theory And Research, 2, 1130-1187.

Mischel, W. (2004).Toward An Integrative Science Of The Person. Annual Review Psychology, 55.1-

Norman, W. T. (1963). Toward an Adequate Taxonomy Of Personality Attributes: Replicated Factor Structure In Peer Nomination Personality Ratings. The Journal of Abnormal and Social Psychology, 66(6), 574.

Osman, M.T. (1989). Malay Folks Beliefs: An Integration Of Disparate Elements. Kuala Lumpur: Dewan Bahasa dan Pustaka.

Park, L. \& Guay, R.P. (2009).Personality, Values, And Motivation. Personality and Individual Differences, 47, 675-684.

Pozzebon, J.A. \& Ashton, M.C. (2009). Personality And Values As Predictors Of-Self-And Peer-Reported Behaviour. Journal of Individual Differences, 30(3): 122129.

Ramaprasad, J. (1998): Relationship and Communication Values Their Reflection In Advertising Information Choices Of Malaysian Youth. Asian Journal of Communication, 8(1), 132-149.

Rokeach, M. (1973). The Nature of Human Values. New York: Free Press.

Schwartz, S. H. (2003). A Proposal for Measuring Value Orientations across Nations. Chapter 7 in the Questionnaire Development Package of the European Social Survey.Website: http://www.europeansocialsurvey.org/index.php?option=com_docman\&;task=doc_view\&gid=126\&Itemid=80.

Schwartz, S. H. (1990). Individualism-collectivism: Critique and Proposed Refinements. Journal of Cross-Cultural Psychology, 21, 139-157.

Schwartz, S.H. (1992). Universals in the Content And Structure Of Values: Theoretical Advances And Empirical Tests In 20 Countries. Advances in Experimental Social Psychology, 25, 1-65.

Schwartz, S. H. (1994). Beyond Individualism/Collectivism: New Cultural Dimensions Of Values. In U. Kim, H.C. Triandis, C. Kagitcibasi, S-C. Choi, \& G. Yoon (Eds.), Individualism and collectivism: Theory, method and applications (pp. 85-119). Newbury Park, CA: Sage.

Swami, V., \& Tovée, M. J. (2005). Female Physical Attractiveness In Britain And Malaysia: A Cross-Cultural Study. Body Image, 2(2), 115-128.

Tupes, E. C., \& Christal, R. E. (1961). Recurrent Personality Factors Based On Trait Ratings (No. ASD-TR-61-97). Personnel Research Lab Lackland AFB TX. 